$17^{\text {th }}$ International Congress of Metrology, 03004 (2015)

DOI: $10.1051 /$ metrology / 201503004

(C) Owned by the authors, published by EDP Sciences, 2015

\title{
Sensor development and calibration method for inline detection of viscosity and solids content of non-Newtonian fluids
}

\author{
Patrick BALLEREAU1,a, Nikola PELEVIC ${ }^{2}$, Jan Jette BLANGE2,8, Inge Van ANDEL2, Ernad BOROVAC ${ }^{3}$, \\ Salvatore LOREFICE ${ }^{4}$, Andreia FURTADO ${ }^{5}$, Marc de HUU ${ }^{6}$, Hugo BISSIG ${ }^{6}$, Henning WOLF ${ }^{7}$, Ronald PAGEL ${ }^{7}$, \\ Svetlana HAGERAATS-PONOMAREVA ${ }^{8}$, Fionn IVERSEN ${ }^{9}$, Maria Teresa CIDADE $^{10}$
}

\author{
${ }^{1}$ LCM LNE-CNAM 1 rue Gaston Boissier 75724 France \\ ${ }^{2}$ VSL Thijsseweg 11, NL-2629 JA Delft, Netherlands \\ 3 IMBiH Augusta Brauna 2, BA-71000 Sarajevo, Bosnia and Herzegovina \\ ${ }^{4}$ INRIM Strada delle Cacce, 91, IT-10135 Torino, Italy \\ 5IPQ Rua António Gião, 2, PT-2829-513 Caparica, Portugal \\ ${ }^{6}$ METAS Lindenweg 50, CH-3003 Bern-Wabern, Switzeland \\ ${ }^{7}$ PTB Bundesalle 100, DE-38116 Braunschweig, Germany \\ ${ }^{8}$ Shell Global Solutions International B.V.Kessler Park 1, 2288 GS Rijswijk Netherlands \\ 9 IRIS Prof. Olav Hanssensvei 15, 4021 Stavanger, Norway \\ ${ }^{10}$ CENIMAT Faculdade de Ciências e Tecnologia and Cenimat/I3N, Universidade Nova de Lisboa, Caparica, Portugal
}

\begin{abstract}
Résumé. Le projet de recherche conjoint EURAMET «Développement et méthode d'étalonnage de capteurs en ligne pour la mesure de la viscosité et du contenu solide» (ENG59-NNL) concerne les fluides de forage, en particulier dans le secteur de l'énergie du pétrole et du gaz. Ce projet regroupe sept laboratoires européens de métrologie, trois compagnies pétrolières, quatre constructeurs d'instruments de rhéologie et des laboratoires de recherches universitaires et industriels. Les fluides de forages contiennent une grande quantité de matières solides. Leur viscosité varie en fonction de la vitesse de cisaillement. Ce sont des liquides non-newtoniens rhéofluidifiant à seuil avec un comportement qui dépend du temps, ils sont thixotropes. Un des buts de ce projet est d'aider au développement de capteurs de mesures en ligne de la viscosité, de la masse volumique, de la concentration et de la distribution en taille de particules solides de ces liquides. Les autres buts de ce projet, sont: de pallier à une absence de norme sur les dispositifs de mesures de viscosité dans le domaine des fluides non-newtoniens, de permettre d'évaluer ces appareils de laboratoires ou ceux qui dans l'avenir pourraient être utilisés en ligne; de développer des matériaux de référence certifiés similaires aux fluides de forage pour les appareils de laboratoire et pour les appareils sur site; de faire enregistrer des CMCs (Calibration and Measurement Capabilities) par les Instituts Nationaux de Métrologie, pour assurer la traçabilité des instruments de mesures. Le projet est présenté sur le site web (www.eng59-rheology.eu). Les premiers résultats de cette étude sont présentés dans cet article.
\end{abstract}

\section{Introduction and background}

When drilling deep for gas and oil or for the purpose of building bridge piles or taking core samples for a future tunnel, non-Newtonian drilling fluids are used.

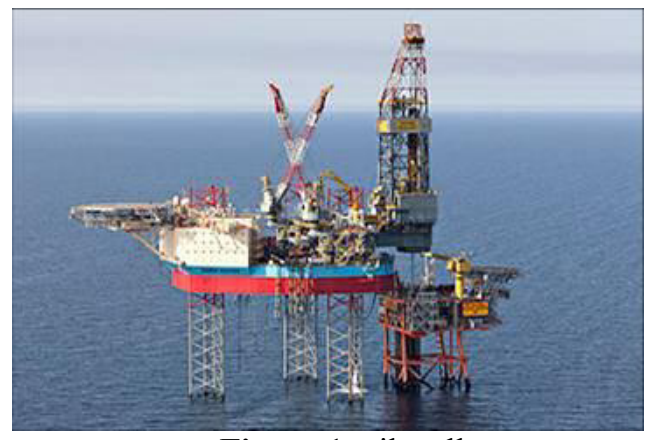

Figure 1. oil well
Such fluids are used for a variety of reasons. The pressurised fluid transports hydraulic power to the down hole drilling assembly and the drill bit, it balances the fluid pressure in the pores of the surrounding formation, stabilises the borehole walls, washes the cuttings out of the well and lubricates the drill bit.

Only special non-Newtonian drilling fluids have this functionality. While drilling, fluid is pumped through the drill string to the drill bit. Typically a drill string has an inner diameter of $15 \mathrm{~cm}$ and a length of 1 to $10 \mathrm{~km}$. The fluid flows through high-pressure nozzles mounted in the bit body against the bottom and flows back to the surface along the inside of the borehole wall taking the drilled cuttings with it. The carrying capacity of the fluid depends on a minimum circulation velocity while the pump pressure required to circulate the fluid should be

\footnotetext{
a corresponding author : patrick.ballereau@cnam.fr
} 
realistic. Moreover, at the moment that a drill pipe has to be added to the drill string, the pumps have to be switched off. In that situation, despite the fact that additional pressure required for circulation is absent, the fluid should keep the drilled solids in suspension, should still stabilise the borehole and balance the fluid pressure in the pores of the borehole formation.

\section{Description of the project}

\subsection{Participants}

The Dutch National Metrology Laboratory VSL is the coordinator of this project.

The other metrology laboratories participating in the project are the following: CNAM (France), IMBiH (Bosnia and Herzegovina), INRIM (Italy), IPQ (Portugal), METAS (Switzerland), PTB (Germany).

IRIS (International Research Institute of Stavanger) in Norway, and Cenimat (Portugal) are participants with Researcher Excellence Grants.

Other partners are involved in the project. There are oil compagnies: Shell (Netherlands), BP (United Kingdom), Statoil (Norway), M-I Swaco; and also rheology instruments manufacturers: Brookfield (USA), Anton Paar (Austria), Thermo (Germany).

There are laboratories in academic and industrial research: CCMM (Portugal), IFPen (France), SIK (Sweden).

\subsection{Need for the project}

To optimise, control and automate the drilling process, accurate and frequent measurement of the viscosity, particle size distribution, solids content and density of the muddy fluid is required.

This is currently done using manually operated, batch type sensors at the surface. However, the accuracy of these devices is limited and not sufficient to perform the required optimisation and automation of the drilling process. Moreover, no in situ calibration procedure that assures a maximum measurement uncertainty currently exists, or directly suitable traceable non-Newtonian reference materials.

Measurement standards exist for producing and measuring Newtonian calibration materials. By using these standards, NMIs are capable of delivering Newtonian viscosity with an accuracy of 0.1 to $0.5 \%$, based on flow through a capillary at low speed. Whether this measurement standard is applicable to nonNewtonian fluids has not been thoroughly investigated, but complications are expected as the flow of shear thinning liquids through a capillary does not have a predictable Poiseuille velocity profile [1].

Therefore, calibration liquids are needed that exhibit non-Newtonian properties. A few such standard reference materials (SRMs) are available. NIST issues two of them, a polymer solution [2] and corn syrup-fine limestone slurry [3]. Furthermore, PTB has completed research to define a polymeric SRM, however this research was discontinued. Since then, non-Newtonian reference materials based on aqueous solutions of synthetic clay particles have come to market. These show little degradation by exposure to shear and over time, which might make them suitable, but they do not possess traceable and consistent properties. There is also no SRM available which can be used to investigate the solid content influence and give a sufficiently good estimation of shear stress at zero strain (gel strength).

In the drilling industry, especially in the oil and gas energy sector, it is very important to have reliable and nearly continuous information on the mentioned physical properties of the fluid. This information is used in models to calculate the down hole pressures and the cuttings carrying capacity.

Four problem areas that currently limit accurate and inline measurement of drilling fluid properties are:

- Fundamental properties of drilling fluids, i.e. high apparent gel strength, high shear thinning properties, large amount of suspended solids, strong time dependent behaviour of viscosity.

- Absence of a (European) guide for calibrating equipment when measuring non-Newtonian fluids, including certified reference materials similar to drilling muds and a method to assess the associated measurement uncertainty.

- No CMCs (Calibration and Measurement Capabilities) registered for non-Newtonian reference materials by any NMI at the BIPM website, in order to show the degree of equivalence between measurements and to provide traceability for the instruments used in the field.

- A lack of sensors for inline viscosity, solids content, PSD (particle size distribution) and density measurement that can cope with strongly non-Newtonian fluids with a high gel strength and large amount of suspended solids.

\subsection{Objectives and activities}

The JRP aims to address these problem areas by developing a traceable calibration method for inline measurements on non-Newtonian liquids, with a strong focus on the drilling fluids used in the oil and gas energy sector. The JRP is divided in five Workpackages (WP's).

WP1 will develop a set of calibration standards in the form of standard reference materials (SRM) for complex fluids in the range of viscosities, densities and temperatures; that are of interest for the stakeholders,

WP2 will study the physical behaviour of complex fluids by means of existing viscometer techniques and rheometers. Current models of the relation between shear rate and viscosity will be compared to experimental results, 
WP3 will focus on sensors and calibration methods for inline measurement of viscosity, density and solids content,

WP4 is designed to maximise the impact of the JRP by creating links to industrial stakeholders,

WP5 is for the management of the JRP.

\section{Progress}

The technical part of the project is divided in three « Workpackages », themselves divided in different tasks. They are defined below with their progress.

\section{WP1: Development of standards for non-Newtonian viscosity}

Task 1.1: Determination of non-Newtonian SRMs specifications

D1.1.1 Confirmation of the completion of a query on operation conditions and a query on the required physical properties for SRMs

The range of operating conditions has been investigated by selected JRPs partners.

D1.1.2 Selection of a range of operating conditions

The range of operating conditions has been selected. A list has been produced regarding the operation range conditions

D1.1.3 Requirements for a set of non-Newtonian SRMs documented

From the query the requirements for the non-Newtonian SRMs have been selected. The requirements document has been produced.

Task 1.2: Method for the production of a set of nonNewtonian SRMs

D1.2.1 Literature study on existing SRMs from NIST and PTB and whether they can to be used as a basis for the production of the non-Newtonian SRMs and report produced

The literature study has been performed. A report with respect to literature study has been produced from PTB.

D1.2.2 Selection of suitable materials to produce the set of non-Newtonian SRMs

Two materials for production of the set of non-Newtonian SRMs are selected. The materials are selected according to the requirements provided in D1.1.3. The materials are in accordance with the requirements.

D1.2.3 Preliminary method for the production of the set of non-Newtonian SRMs

Preliminary method for the production of the set of nonNewtonian SRMs has been established. This method will be used for SRMs production.
Task 1.3: Experimental validation of the set of nonNewtonian SRMs

Task 1.4: Comparison of the set of non-Newtonian SRMs

Task 1.5: Uncertainty budget for the set of nonNewtonian SRMs

\section{WP2: Review of the impact of non-Newtonian physics} on rheology measurement techniques

Task 2.1: Effect of solids on rheology and existing rheometry methods

The first task of WP2 consists mostly of a literature study where the relevant rheometry principles and the influence of solid content of slurries on their rheological behaviour are described. Particle properties of complex liquids used in the field and their impact on rheology have been identified and a possible candidate for a Standard Reference Material (SRM) has been identified. CFD simulations are currently being performed to study the influence of solid particles on the velocity and velocity gradient field in a rheometer for a Newtonian fluid.

D2.1.1 Identification of existing or potential relevant rheometry principles for the study of viscoelastic behaviour of complex fluids

D2.1.2 Report on the review of the influence of the solid content of slurries on their rheological behaviour

D 2.1.3 Identification of relevant particle properties of complex liquids used by stakeholders in order to determine their impact on non-Newtonian fluid rheology (viscosity, density, shear dependency, solid content) based on literature studies from D2.1.1 and D2.1.2

Task 2.2: Wall slip

Task 2.3: Gellation and gel breaking

\section{WP3: Inline integrated sensors and calibration techniques}

Task 3.1: Review of existing viscosity sensors and alternative relevant sensor technology

D3.1.1 List of existing instruments applicable for the inline measurement of viscosity, density and solids

D3.1.2 Report on the applicability of existing instruments and other relevant techniques for the measurement of viscosity, density and solids content under operational conditions in D1.1.2

D3.1.3 Recommendations for improvement of existing sensors and calibration techniques for the inline measurement of viscosity, density and solids content under the operational conditions defined in D1.1.2 
Task 3.2: Rheology sensors

Task 3.3: Density sensors

Task 3.4: Detection of solids content

Task 3.5: Selection of the inline rheometer for the full scale verification

Task 3.6: Full scale verification of the selected inline rheometer

\section{Conclusion}

The energy sector is not the only industry in which it is important to monitor the non-Newtonian properties of fluids. For many manufacturers of food, paint, slurries, body care and pharmaceutical products the viscosity, density and solids content is very important for quality and process control. Similar to the drilling industry, many chemical plants require measurements to be taken in hostile working environments and to be able to do this automatically with suitable inline equipment would be a major step forward.

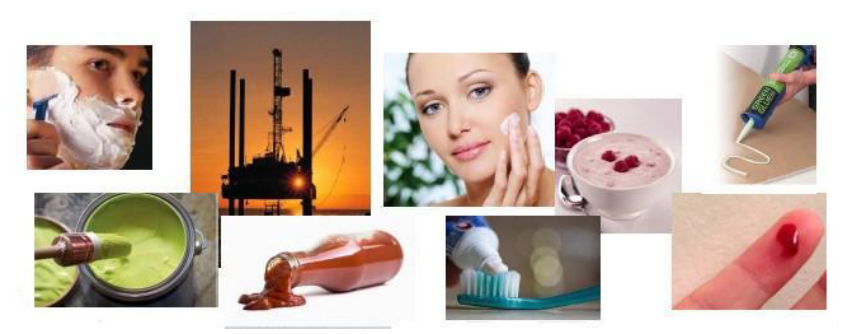

This work is part of the European Metrology Research Program (EMRP) ENG59-NNL project. It received funding from EMRP participating countries within EURAMET and European Union.

\section{References}

1. R.P. Chhabra, J.F. Richardson, Non-Newtonian Flow and Applied Rheology (Second Edition), Elsevier (2008)

2. National Institute of Standards and Technology, NIST Special Publication 260-143, Certification of the Rheological Behavior of SRM 2490, Polyisobutylene Dissolved in 2,6,10,14 -Tetramethylpentadecane, (2002)

3. National Institute of Standards and Technology, NIST Special Publication 260-174, Certification of SRM 2492, Bingham Paste Mixture for Rheological Measurements, Rev. (2012) 